\title{
NOLL, João Gilberto. Mínimos, múltiplos, comuns. São Paulo: Francis, 2003.
}

Ana Martins Marques

Universidade Federal de Minas Gerais

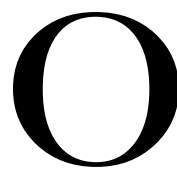

escritor gaúcho João Gilberto Noll publicou, no jornal Folha de $S$. Paulo, entre agosto de 1998 e dezembro de 2001, em uma pequena coluna intitulada "Relâmpagos", uma série de textos breves, cada um com no máximo 130 palavras. São 338 relatos mínimos, que exploram regiões limítrofes entre a prosa e a poesia, e que, no final de 2003, apareceram em livro, em cuidadosa edição, sob o título Minimos, múltiplos, comuns. Redução de escala, mas não de valor, de uma obra consolidada, mas que sabe ainda provocar e lançar-se a novos trajetos.

O lançamento de Mínimos, múltiplos, comuns, depois de nove romances, marca a volta de Noll ao conto, agora brevíssimo, retomando a variedade narrativa presente em seu fundamental livro de estréia, O cego e a dançarina, e que parecia ter sido abandonada em sua produção posterior, em virtude da opção por uma narrativa monológica que segue de perto o moto-contínuo de um narrador masculino constantemente em trânsito.

A indagação sobre o esgotamento da voz narrativa, tão presente nos contos de seu primeiro livro, conduziu a ficção de Noll, em um movimento paradoxal, a um alongamento do texto, à passagem da forma do conto para a forma do romance, mesmo que extremamente breve. Depois de O cego e a dançarina, Noll escreveu dois romances longos ( A fúria do corpo e, embora em menor medida, Bandoleiros), publicou uma série de narrativas curtas, que, pelo tamanho, mais se aproximam de novelas (Rastros do verão, Hotel Atlântico, O quieto animal da esquina, Harmada), um outro romance de maior extensão ( $A$ céu aberto), passou pelos contos 
mínimos de "Relâmpagos" e retomou a narrativa breve, com Canoas e Marolas e Berkeley em Bellagio. Esse percurso pela obra em termos de escala, de dimensão, mostra a variação de formas (conto, romance, novela, miniconto) adotadas pelo autor e revela uma certa inquietude na formalização, como se a questão da "variação sistemática de escala" ${ }^{1}$ que Flora Süssekind localiza na literatura e na arte brasileiras contemporâneas se manifestasse na obra de Noll nesses exercícios de extensão variada que a compõem.

Como os contos de O cego e a dançarina, os textos curtos que integram o Minimos, múltiplos, comuns exploram a variação de foco, de recursos e registros. Assumem a voz, além do narrador em terceira pessoa, mulheres, homens e crianças, flagrados em atos cotidianos ou em súbitas revelações, em momentos de abandono ou metamorfose, ou ainda prestes a atravessar uma fronteira, linha delicada que os separa do que "até então não era de seu campo" ("Amazônico").

Coágulos de instantes ou flashes de lembranças, registros de gestos e posturas, mínimas sagas ou retratos $3 \times 4$ de delírios instan- tâneos, esses contos assumem a rapidez como procedimento narrativo, com a pluralidade e a experimentação a que convidam as formas breves. Em movimentos simultâneos de concentração e rarefação, de velocidade e espera, os contos parecem artefatos que suspendem, por um momento mínimo, o fluxo de uma narrativa a princípio mais extensa, mas que ao mesmo tempo só existe ali, no rápido instante da cena: quadros autônomos capturados, de relance, pela tela do texto.

Narrativas? Apenas se um gesto, o movimento do dia, uma espera, o ato de beber um copo d'água, de olhar as próprias mãos, de estender os lençóis, um amor que não leva a nada, uma falha da memória puderem ser considerados narrativas. Ou se fragmentos de cenas cujas ações precedentes e subseqüentes são ignoradas, que não deixam entrever suas motivações, forem, em si mesmos, histórias - vestígios de um crime ignorado, lençóis sujos de sangue, a criança que sai andando a esmo do local do acidente que não consegue ver, sentindo na boca o ardor do primeiro cigarro. A ação, sempre presente nos textos de Noll, submete-se a um andamento lírico,

\footnotetext{
${ }^{1}$ SÜSSEKIND, 2000, p. 4.
} 
aproximando seus contos breves da tradição do poema em prosa, essa "forma informe" ${ }^{2}$ que nasce com a poesia moderna, com Baudelaire e Rimbaud.

Para compor esse Minimos, múltiplos, comuns, os textos foram agrupados pelo autor em cinco grandes conjuntos - Gênese, Os elementos, As criaturas, O mundo e O Retorno -, que por sua vez se dividem em outras seções. Mais do que simplesmente organizá-los tematicamente ou revelar o arranjo secreto que os uniria, o trabalho de articulação que Noll realiza faz surgir um modo de leitura a partir do qual os contos podem ser recombinados, relidos, desdobrados - não como o papel dobrado em forma de barco que se transforma novamente em folha lisa, mas como o botão que se desdobra em flor, para usar a bela imagem construída por Walter Benjamin para ler os textos curtos de Kafka, alguns deles tão reduzidos quanto as microficções de Noll. Dessa ordenação resulta um livro de incerta classificação "desqualificado para o convívio sensato das formas", como o "Gigante" de um dos relatos.
Os contos, a princípio dispersos, passam a compor uma cosmogonia: uma gênese do mundo e dos corpos, dos nomes, dos bichos e das plantas, e suas incessantes metamorfoses. Seria possível, certamente, encontrar outros arranjos para os textos. "Na correnteza", por exemplo, caberia na seção Mutações, "Mafuá" se encaixaria perfeitamente no conjunto intitulado Reflexos e o conto que abre o livro poderia facilmente encerrá-lo. Prova de que, no cosmo nolliano, não há direção exclusiva e o princípio é a variação: as coisas e seus lugares participam da indefinição fundamental de onde partem, e com que ímpeto.

Ao mesmo tempo que ensaiam uma retomada, em miniatura, da diversidade e da experimentação características do primeiro livro de Noll, os mínimos, múltiplos, comuns apresentam temas e procedimentos que remetem a toda a sua ficção: personagens andarilhos e amnésicos, que, incapazes de constituir uma consciência do tempo, desprendem-se do ritmo de seus afazeres e encenam a cada momento a

${ }^{2}$ A expressão é retirada do editorial do $\mathrm{n}^{\circ} 14$ da revista Inimigo Rumor, publicado no $1^{\mathrm{o}}$ semestre de 2003 e dedicado ao poema em prosa. 
própria identidade; a indistinção entre memória, fato e alucinação; o diálogo com o cinema ("As asas de Kane", "Fusão", "A sessão", "Cultivo"); a errância do corpo e do pensamento; a atenção ao mundo contemporâneo, com suas marcas geográficas, políticas e culturais ("Línguas", "Noites cariocas", "Prodígios"), aspecto central no último livro do autor, Berkeley em Bellagio; e, ainda, uma abertura para forças telúricas, inaugurais, presente já em Harmada e A céu aberto, e que revela, nessa ficção predominantemente urbana, o intenso "amor dos elementos" que a atravessa: "De si como que desciam filamentos ao encontro do capim, da terra", lê-se em "Quieta duração".

O sujeito que esses quadros rápidos colocam em cena está sempre em mutação, sempre prestes a sair de si e ligar-se a algo que já não é o si, mas o outro: "Ela estava agora fora do alcance até de si mesma, já era substância de uma outra, alguém que de fato nunca vira em seus embalos, flutuações, transtornos." ("Adão"). Um outro que não é necessariamente humano, mas pode também ser bicho, pedra ou flor, água ou nuvem, sonho ou cinema. Chama a atenção, sobretudo, a ênfase com que, nesses textos, os sujeitos desaparecem, fundidos no mundo, esvaídos na velocidade ou misturados às imagens de um filme qualquer: "No cinema, ele percebe. Participa pela primeira vez do enredo de um filme. Seu braço esverdeado funde-se a outro, violeta." ("A sessão"). Sempre dado a apresentar identidades móveis, de passagem - personagens em permanente deslocamento, não apenas geográfico, mas também sexual e social; narradores atores, como o de Harmada, que seguem encenando monólogos ininterruptos, duvidando, porém, a cada momento, da própria possibilidade de dizer "eu"; estrangeiros em qualquer lugar, como o narrador de Berkeley em Bellagio, que chega a esquecer a própria língua -, Noll trata agora de sujeitos à beira de esvaírem-se, para sempre desprendidos de uma identidade, em um movimento de dispersão e autoapagamento, de alegre desaparecimento.

\section{A coagulação do instante}

\section{Cultivo}

Ele caminhava aos poucos. Era esse o recurso que usava para encontrá-la na oitava fila do cinema, quem sabe numa penumbra não muito fechada, dessas que envolvem algum personagem de 
filme no ato de assistir a um outro filme. Personagem, sim, condenado à exposição ininterrupta de seu próprio enredo. Era esse o recurso: dirigir-se aos poucos, em pequenas doses. Esse o meio-tom, pois não deveria vê-la com toda a nitidez, não deveria reconhecê-la com absoluta segurança. Nada lhe despertaria uma sensação plenamente familiar, enfim. Ela estava à espera. E por que não se virava para confirmar o encontro? Estava ali, totalmente absorta na tela. Ele não sabia se aquele corpo era de fato o dela. Apenas encostou, como um cego. A mulher respondeu. E o guiou até o centro de toda a palpitação.

Uma pequena cena. Um homem que busca uma mulher em uma sala de cinema, uma aproximação hesitante, um encontro na penumbra, corpos indefinidos que se encostam e que respondem ao contato. Nada sabemos dele, nada sabemos dela, desconhecemos que tipo de relação eles mantêm, não sabemos onde fica esse cinema, a que hora do dia ou da noite se dá essa sessão de não se sabe qual filme. A cena é sem passado e sem futuro. Ela é.

Do ponto de vista do enunciado, podemos pensar o termo "cultivo", que dá título ao conto, como remetendo a uma espécie de educação sentimental da personagem. Temos, no conto, a narração de um encontro na penumbra de um cinema, a espera (dela), a hesitação (dele), e finalmente o contato dos corpos, a viagem ao "centro de toda a palpitação". É interessante que o encontro se dê no cinema, lugar por excelência, para uma certa geração, de formação, não apenas intelectual, mas também afetiva. Mas pode-se também pensar o termo "cultivo" como remetendo à criação do conto, o que abre a possibilidade de ler o texto como uma problematização de seu próprio processo narrativo.

"Era esse o recurso: dirigir-se aos poucos, em pequenas doses". Frase que não deixa de chamar a atenção em um espaço destinado a textos mínimos, pequenas doses. Esse o recurso. Como se a lógica interna do conto ditasse sua formalização, sua dimensão reduzida e sua atmosfera a meio-tom. Lemos no conto, simultaneamente, a hesitação do narrador que se dirige a um encontro e a hesitação do próprio texto, que se debate entre revelar e ocultar, e permanece à meia-luz, distanciando-se da nitidez e do reconhecimento plenamente familiar, mas sem impedir que, afinal, o encontro se dê. O que está aqui em exposição, portanto, é não 
apenas o narrador, mas também o próprio processo narrativo. "Condenado à exposição de seu próprio enredo", o texto discute seus recursos expressivos, seus procedimentos, sua dimensão. "O homem de hoje não cultiva o que não pode ser abreviado", diz Paul Valéry, em um trecho citado por Benjamin, que logo em seguida o comenta: "Com efeito, o homem conseguiu abreviar até a narrativa"'. Mudança de temporalidade que repercute no processo de formação da narrativa, nos modos do seu "cultivo".

Se podem ser pensados a partir de sua inserção no movimento de miniaturização recorrente na prosa de ficção brasileira recente (que inclui, por exemplo, os minicontos de Modesto Carone e Dalton Trevisan, os quase-poemas narrativos de Zulmira Ribeiro Tavares, cada uma das faixas do
Stereo de um estudioso da ficção de Noll, Mauricio Salles Vasconcelos, e o empenho oulipotiano-liliputiano dos autores de Os cem menores contos brasileiros do século, organizado por Marcelino Freire), os mínimos, múltiplos, comuns podem também ajudar a esclarecer vários aspectos do universo ficcional de Noll. Nesses textos brevíssimos, o autor gaúcho pôde experimentar, em um espaço mínimo e por isso mesmo com uma maior radicalidade, o redimensionamento do acontecimento, a autonomização da cena, a indagação sobre o papel do narrador e a poetização da narrativa, que passa a ser guiada menos pelo fio de um enredo que pelo fluxo das imagens, por seus ritmos e arritmias. Retomada e exploração, em escala reduzida, do horizonte narrativo em que se move a ficção de João Gilberto Noll.

\section{Referências Bibliográficas}

BENJAMIN, Walter. Obras escolbidas I. Magia e técnica, arte e política. Trad. Sérgio Paulo Rouanet. 3. ed. São Paulo: Brasiliense, 1987.

INIMIGO RUMOR, São Paulo, n.14, 1ํㅗ. sem. 2003.

SÜSSEKIND, Flora. Escalas e ventríloquos. Folha de S. Paulo, domingo, 3 de julho de 2000. Mais! p. 4-11.

${ }^{3}$ BENJAMIN, 1987, p. 206. 